\title{
Pelatihan Alat Musik Gamolan Lampung untuk Forum Mulei Menganai Panaragan sebagai Peningkatan Keterampilan Kesenian Tradisional Lampung di Tiyuh Panaragan Kabupaten Tulang Bawang Barat
}

\author{
Erizal Barnawi ${ }^{*}$, Ricky Warman Putra ${ }^{2}$, Laras Amelia Winny ${ }^{1}$, Amelia Tri \\ Amanda $^{1}$ \\ ${ }^{1}$ Pendidikan Musik, Lampung University, Bandar Lampung, 35145, Lampung, Indonesia \\ ${ }^{2}$ Pendidikan Tari, Lampung University, Bandar Lampung, 35145, Lampung, Indonesia
}

\begin{abstract}
.
Pembelajaran pokok bahasan Musik sebagai bagian dari media kerterampilan seni dan budaya di Forum Muli Menganai Panaragan Kampung Panaragan, Kabupaten Tulang Bawang Barat yang selama ini kurang memenuhi tingkat kreatifitas dan pengembangan seni budaya Lampung. Pelajaran biasanya sekedar diisi dengan bernyanyi klasikal dilanjutkan individual, kurang menyiratkan unsur-unsur musik yang sedemikian kaya terutama unsur irama dan unsur melodi. Alat musik Gamolan merupakan salah satu alat musik tradisi yang sangat praktis, sangat memungkinkan para muda mudi Tiyuh Panaragan menggunakan alat musik tersebut sebagai media pembelajaran dan menguntungkan dalam upaya meningkatkan penguasaan pemuda dalam hal unsur-unsur irama dan unsur-unsur melodi tersebut. Jika para muda mudi Tiyuh Panaragan mampu memainkan Gamolan lambat laun akan mempunyai rasa puas dan rasa irama yang benar. Kegiatan ini dibatasi pada pelatihan memainkan alat musik Gamolan dengan beberapa lagu yaitu: tabuh layang kasiwan dan tabuh alau-alau, tabuh rajo menggalo, tabuh sermendung sirlia, dan tabuh gupek dan tabuh tari dalam iringin tari Sigeh Penguten. Metode ceramah oleh pelaksana untuk menjelaskan manfaat kemampuan bermain Gamolan, bagian-bagian Gamolan, dan cara bermain Gamolan yang baik dan benar. Serta, memperagakan secara langsung oleh pelaksana pengabdian untuk memberikan contoh memainkan Gamolan dengan tabuh layang kasiwan, tabuh Alau-alau. tabuh rajo menggalo, tabuh sermendung sirlia, dan tabuh gupek dan tari dalam iringin tari Sigeh Penguten.
\end{abstract}

Keywords.

Gamolan, Kreatifitas, Forum Muli Menganai Tiyuh Panaragan

* Corresponding author: erizalbarnawi@yahoo.co.id

Received 05 October 2021; Received in revised form 16 October 2021; Accepted 17 October 2021

Available online 27 December 2021

Lembaga Penelitian dan Pengabdian Kepada Masyarakat

Universitas Lampung 


\section{PENDAHULUAN}

\section{Analisis Situasi}

Pembelajaran pokok bahasan Musik sebagai bagian dari pembelajaran seni dan budaya di Forum Muli Menganai (FMM) Panaragan, Tiyuh Panaragan, Kabupaten Tulang Bawang Barat, selama ini kurang memenuhi tuntutan kreatifitas dan keterampilan. Pelajaran biasanya sekedar diisi dengan bernyanyi klasikal dilanjutkan individual, kurang menyiratkan unsur-unsur musik yang sedemikian kaya terutama unsur irama dan unsur melodi.

Gamolan merupakan salah satu alat musik tradisi yang sangat praktis, sangat menguntungkan dalam upaya meningkatkan penguasaan para muda mudi dalam hal unsurunsur irama dan unsur-unsur melodi tersebut. Jika para muda mudi mampu memainkan Gamolan lambat laun akan mempunyai rasa puas dan rasa irama yang benar.

Kegiatan ini dibatasi pada pelatihan memainkan Gamolan dengan beberapa buah tabuhan/lagu yaitu: tabuh layang kasiwan, Tabuh alau-alau, tabuh Alau-alau. tabuh rajo menggalo, tabuh sermendung sirlia, dan tabuh gupek dan tari dalam iringin tari Sigeh Penguten

Menurut pengamatan langsung dari pelaksana pengabdian kepada masyarkat, ada beberapa muda mudi Tiyuh Panaragan yang bisa memainkan alat musik Gamolan. Dari 50 muda mudi tiyuh panaragan tersebut dalam hal: 1) Kemampuan memainkan Gamolan 85\% belum memahami; 2) Memainkan beberapa tabuhan di alat musik Gamolan belum banyak yang mengerti. Akhirnya, berdasarkan dari hasil pengamatan langsung tersebut dipandang perlu diadakan pembelajaran memainkan Gamolan bagi Forum Mulei Menganai Tiyuh Panaragan, Kabupaten Tulang Bawang Barat.

\section{Permasalahan Mitra}

Berdasarkan hasil survey diketahui bahwa:

1. $85 \%$ Forum Mulei Menganai Tiyuh Panaragan, Kabupaten Tulang Bawang Barat belum memahami manfaat, dan mampu memainkan alat musik Gamolan Lampung.

2. $85 \%$ Forum Mulei Menganai Tiyuh Panaragan, Kabupaten Tulang Bawang Barat belum mampu memainkan tabuh layang kasiwan.

3. $85 \%$ Forum Mulei Menganai Tiyuh Panaragan, Kabupaten Tulang Bawang Barat belum mampu memainkan tabuh alau-alau.

4. $85 \%$ Forum Mulei Menganai Tiyuh Panaragan, Kabupaten Tulang Bawang Barat belum mampu memainkan tabuh rajo menggalo.

5. $85 \%$ Forum Mulei Menganai Tiyuh Panaragan, Kabupaten Tulang Bawang Barat belum mampu memainkan tabuh sermendung sirlia,

6. $85 \%$ Forum Mulei Menganai Tiyuh Panaragan, Kabupaten Tulang Bawang Barat belum mampu memainkan tabuh gupek dan tari dalam iringin tari Sigeh Penguten

Maka dapat dikatakan masalahnya adalah:

1. Apakah usaha yang harus dilakukan supaya Forum Mulei Menganai Tiyuh Panaragan, Kabupaten Tulang Bawang Barat belum mampu memainkan memahami manfaat memainkan alat musik Gamolan Lampung?

2. Apakah usaha yang harus dilakukan supaya Forum Mulei Menganai Tiyuh Panaragan, Kabupaten Tulang Bawang Barat belum mampu memainkan mampu memainkan Tabuh Layang Kasiwan?

3. Apakah usaha yang harus dilakukan supaya Forum Mulei Menganai Tiyuh Panaragan, 
Kabupaten Tulang Bawang Barat belum mampu memainkan mampu memainkan Tabuh Alau-alau?

4. Apakah usaha yang harus dilakukan supaya Forum Mulei Menganai Tiyuh Panaragan, Kabupaten Tulang Bawang Barat belum mampu memainkan mampu memainkan Tabuh Rajo Menggalo?

5. Apakah usaha yang harus dilakukan supaya Forum Mulei Menganai Tiyuh Panaragan, Kabupaten Tulang Bawang Barat belum mampu memainkan mampu memainkan Tabuh Sermendung Sirlia?

6. Apakah usaha yang harus dilakukan supaya Forum Mulei Menganai Tiyuh Panaragan, Kabupaten Tulang Bawang Barat belum mampu memainkan mampu memainkan Tabuh Gupek dan Tabuh Tari dalam tari Sigeh Penguten?

\section{TINJAUAN PUSTAKA}

Pelajaran Kesenian yang diajarkan di Sekolah Menengah Pertama (SMP) hingga Sekolah Menengah Atas (SMA) merupakan pelajaran yang wajib ditempuh oleh seluruh siswa, namun kali ini pelatihan dipusatkan pada forum muda-mudi atau Mulei Menganai Panaragan yang sampai saat ini melestarikan kesenian Lampung. Pelajaran ini bertujuan untuk menumbuhkan kreativitas dan meningkatkan kemampuan muda-mudi dalam berinteraksi dengan cara memberikan tugas-tugas berkelompok. Memperkaya pengalaman estetik muda-mudi terhadap karya musik, serta menumbuhkan rasa memiliki muda-mudi yang akan ditularkan ke siswa terhadap seluruh kekayaan seni yang ada di Nusantara.

Materi yang diberikan adalah seni musik tradisional Lampung (Gamolan). Pada kurikulum 2013 sekolah menengah, pelajaran kesenian diwadahi oleh mata pelajaran seni budaya. Tujuan mata pelajaran ini adalah sebagai berikut.

1. Mengembangkan sikap toleransi, demokrasi, beradab dan rukun dalam masyarakat majemuk.

2. Mengembangkan intelektual, imajinasi dan ekspresi melalui seni.

3. Mengembangkan kepekaan rasa, keterampilan dan kreativitas.

4. Menerapkan teknologi dalam berkarya dan dalam menampilkan karya seni.

5. Menanamkan pemahaman tentang dasar-dasar kesenian.

Tujuan dari pembelajaran ini adalah:

1. Memperkenalkan dan melatih muda-mudi agar tahu terhadap lingkungannya, ikut melestarikan budaya termasuk kerajinan, keterampilan yang nilai ekonominya tinggi di daerah tersebut.

2. Membekali muda-mudi agar kemampuan dan keterampilan yang dapat menjadi bekal untuk mengajarkan kembali kepada rekan-rekannya.

Berdasarkan UU No. 2 Tahun 1989, Bab 1, Pasal 1, Pendidikan adalah usaha sadar untuk menyiapkan siswa melalui kegiatan bimbingan,pengajaran,dan latihan bagi peranannya dimasa yang akan datang. Salah satu fungsi pendidikan yaitu untuk menyiapkan siswa yang baik dan berkualitas untuk membangun bangsa dan Negara yang baik. Oleh karna itu pendidikan berfungsi untuk menyiapkan siswa yang pada hakikatnya belum siap dan perlu disiapkan. Untuk menyiapkan siswa yang berkualitas baik,maka diperlukan peran seorang guru yaitu guru yang dapat memberikan bimbingan, pengajaran ataupun latihan [1].

Salah satu bahan yang bisa dikembangkan melalui kegiatan kreatif pada pelajaran kesenian adalah melalui rangsang awal. Rangsang merupakan suatu kegiatan yang membangkitkan fikir dan semangat, khususnya dalam motivasi siswa memainkan alat 
musik. Berbagai rangsangan yang dapat memotivasi siswa bergerak kreatif yaitu rangsangan auditif, visual, gagasan, dan rabaan atau kinestetik [2].

Bruce Joyce dan Masha Weil (1980) dalam bukunya Models of Teaching mengemukakan empat rumpun model mengajar yakni sebagai berikut [3]:

1. Information processing models yang berorientasi pada pengembangan kemampuan peserta didik dalam mengolah dan menguasai informasi yang diterima dengan menitikberatkan pada aspek intelektual akademis.

2. Personal models yang berorientasi kepada pengembangan diri (pribadi) peserta didik, baik sebagai individu maupun dalam hubungannya dengan lingkungan, dengan menitikberatkan pada aspek kehidupan emosional.

3. Social interaction models yang berorientasi kepada pengembangan kemampuan peserta didik dalam bekerjasama dengan orang lain, berperan aktif dalam proses demokratis dan bekerja dengan produktif di dalam masyarakat dengan menitikberatkan aspek kehidupan sosial.

4. Behavioral models yang berorientasi kepada kemampuan menguasai fakta, konsep, keterampilan, dan kemampuan mengurangi kecemasan serta miningkatkan ketenangan dengan menitikberatkan pada aspek perbuatan perilaku yang dapat diamati.

Mengacu pada pendapat yang dijabarkan di atas, maka dalam pembelajaran seni hendaknya harus disertai dengan media-media yang mampu mewadahi agar tujuan yang diharapkan tercapai. Seni musik tradisional Lampung contohnya, pengajar harus menyediakan alat musik tradisional Lampung seperti gamolan, rebana, dan talobalak.

\section{MATERI DAN METODE PELAKSANAAN}

\section{Kerangka Pemecahan Masalah}

Salah satu cara untuk menambah keterampilan dan kemampuan Forum Mulei Menganai Panaragan dalam berolah seni yaitu dengan cara mengadakan pelatihan seni. Kurangnya tenaga pengajar seni yang professional sehingga muda-mudi tidak bisa mengexpresikan keinginan mereka. Maka diadakan pelatihan muda-mudi seni se-kota Forum Mulei Menganai Panaragan untuk memperkenalkan alat musik tradisional Lampung yaitu Gamolan Lampung.

Berdasarkan tujuan di atas maka pemecahan masalah ini adalah sebagai berikut:

1. Persiapan meliputi:

a. Makalah tentang berbagai bentuk seni yang berisi tentang informasi musik tradisional Lampung (Gamolan)

b. Menyiapkan alat musik Gamolan

2. Pembukaan pelatihan

3. Penyampaian materi oleh nara sumber. Penyampaian materi dilakukan dengan cara mendemonstrasikan alat musik tradisional Lampung (gamolan) dan mempraktikkannya.

4. Pelatihan diakhiri dengan cara muda-mudi memainkan alat musik tradisional Lampung yang terdiri dari gamolan dan rebana. 
Tabel 1. Kerangka Pemecahan Masalah

\begin{tabular}{lll}
\hline \multicolumn{1}{c}{ Kondisi saat ini } & Perlakuan yang diberikan & Kondisi yang diharapkan \\
\hline Adanya sejumlah muda- & Mendemonstrasikan & Bertambahnya kemampuan \\
mudi yang belum & beberapa bentuk tabuhan & muda-mudi dalam \\
mengetahui tentang musik & dengan menggunakan alat & berekspresi atau \\
tradisional Lampung & musik tradisional Lampung & $\begin{array}{l}\text { berkreativitas dengan } \\
\text { menggunakan alat musik } \\
\text { tradisional Lampung }\end{array}$ \\
\hline
\end{tabular}

\section{Pelaksanaan Pemecahan Masalah}

Pelaksanaan pemecahan masalah dilakukan dalam bentuk kegiatan pelatihan. Sebelum pelatihan ini dilaksanakn terlebih dahulu ada surat permohonan pelatihan seni musik tradisional Lampung kemudian surat tersebut mendapat respon positif dari Universitas Lampung dan memberikan surat tugas kepada Erizal Barnawi, M.Sn sebagai ketua pelaksana yang di ketahui oleh sekretari Lembaga Penelitian Pengabdian Kepada Masyarakat Univerisitas Lampung.

Adapun pesertanya dalam pelatihan ini adalah Muda-mudi se-Tiyuh Panagaran (Forum Mulei Menganai) Kecamatan Tulang Bawang Tengah, Kabupaten Tulang Bawang Barat berjumlah 30 Orang. Berikut adalah nama-nama peserta yang mengikuti latihan.

Tabel 2. Daftar Nama Peserta Pelatihan Gamolan

\begin{tabular}{cll}
\hline No. & \multicolumn{1}{c}{ NAMA } & \multicolumn{1}{c}{ INSTANSI } \\
\hline 1 & Irawan Syah & Forum Mulei Menganai Panaragan \\
2 & Tajri, S.Pd. & Forum Mulei Menganai Panaragan \\
3 & Meladi Ys & Forum Mulei Menganai Panaragan \\
4 & Sony afandi & Forum Mulei Menganai Panaragan \\
5 & Edo Wardana & Forum Mulei Menganai Panaragan \\
6 & Faizal & Forum Mulei Menganai Panaragan \\
7 & Sandi kurniawan & Forum Mulei Menganai Panaragan \\
8 & Rezky Wahyu & Forum Mulei Menganai Panaragan \\
9 & Zulniawan & Forum Mulei Menganai Panaragan \\
10 & Dedi putra irawan & Forum Mulei Menganai Panaragan \\
11 & Rahmat ari wandi & Forum Mulei Menganai Panaragan \\
12 & Antoni & Forum Mulei Menganai Panaragan \\
13 & Fitria Oktaviani & Forum Mulei Menganai Panaragan \\
14 & Ella mutiyanti & Forum Mulei Menganai Panaragan \\
15 & Dina aprisa & Forum Mulei Menganai Panaragan \\
16 & Fera listina & Forum Mulei Menganai Panaragan \\
17 & Yuranti Persatika. A. Md. Kes & Forum Mulei Menganai Panaragan \\
18 & Noviansyah ali & Forum Mulei Menganai Panaragan \\
19 & Veri Romadhoni & Forum Mulei Menganai Panaragan \\
20 & Veri Yadi & Forum Mulei Menganai Panaragan \\
21 & Anisa Melani Putri & Forum Mulei Menganai Panaragan \\
22 & Laudya Bella & Forum Mulei Menganai Panaragan \\
23 & Jessica Rahma Wati & Forum Mulei Menganai Panaragan \\
24 & Fina Lismita & Forum Mulei Menganai Panaragan \\
25 & Andre Bhayangkara & Forum Mulei Menganai Panaragan \\
26 & Nopriwan Saputra & Forum Mulei Menganai Panaragan \\
27 & Devriyansah & Forum Mulei Menganai Panaragan \\
28 & Ardhian Saputra & Forum Mulei Menganai Panaragan \\
29 & Rianda Aditya Frandico & Forum Mulei Menganai Panaragan \\
30 & Riyan Suardi & Forum Mulei Menganai Panaragan \\
\hline & &
\end{tabular}

Setelah pembukaan pelatihan secara resmi, pelatihan dimulai dengan tes awal. Hasil tes digunakan untuk mengetahui persentase peningkatan yang dicapai oleh peserta dalam pelatihan ini. Selain tes awal penyajian juga diawali dengan penjelasan tentang materi yang akan di jelaskan dengan menggunakan metode demonstrasi dan praktik. Penyajian materi dibagi menjadi 4 sesi masing-masing pateri yaitu perkenalan dan sejarah alat musik 
tradisional Lampung, tehnik memainkan alat musik, menjelaskan tabuhan yang akan dimainkan dan mempraktikkannya.

\section{Khalayak Sasaran}

Sasaran kegiatan pelatihan ini adalah Muda-mudi se-Tiyuh Panagaran (Forum Mulei Menganai) Kecamatan Tulang Bawang Tengah, Kabupaten Tulang Bawang Barat. Hal ini dilakukan agar muda-mudi dapat mengasah kemampuannya dalam bidang seni musik serta meningkatkan sense of art muda-mudi terhadap seni tradisi Lampung dalam pelatihan ini juga memberikan kesempatan muda-mudi bagaimana berinteraksi dengan baik, bagaimana cara menghadapi orang lain. Misalnya dibentuk secara berkelompok untuk berlatih memainkan alat musik tradisional Lampung.

\section{Keterkaitan}

Pelatihan ini diharapkan menjalin kerjasama antara dosen-dosen Jurusan Bahasa dan Seni Program Studi Pendidikan Musik dengan para pemangku kepentingan di Tiyuh Panaragan dalam rangka sosialisasi Program Studi Pendidikan Musik di Fakultas Keguruan dan IImu Pendidikan Universitas Lampung.

\section{Metode Kegiatan}

Metode yang digunakan dalam hal ini adalah sebagai berikut:

1. Metode demonstrasi

Metode demontrasi adalah suatu cara mengajar dengan mempertunjukkan sesuatu atau mendemontrasikan sesuatu. Pada pelatihan ini narasumber mendemonstrasikan materi yang direncanakan. Metode ini diharapkan menambah wawasan muda-mudi tentang Gamolan musik tradisional Lampung serta dapat dijadikan sebagai keahlian guru.

2. Metode pemberian tugas

Metode pemberian tugas merupakan metode yang memberikan kesempatan kepada muda-mudi untuk memperagakan seluruh materi yang diberikan secara berkelompok.

\section{Rancangan Evaluasi}

Evaluasi adalah suatu usaha yang dilakukan seseorang untuk mengumpulkan berbagai data atau informasi tentang proses atau hasil belajar yang dicapain oleh peserta melalui kegiatan belajar mengajar. Adapun tujuan umum evaluasi adalah memanfaatkan informasi yang didapat untuk dijadikan dasar unruk menentukan perlakuan berikutnya. Evaluasi dalam penelitian ini akan dilakukan pada awal pelatihan, pada saat proses pelatihan berlangsung dan ketika pelatihan berakhir.

a. Evaluasi awal dimaksudkan untuk mengetahui pemahaman peserta terhadap materi seni yang akan diberikan. Evaluasi ini dilakukan dengan cara memberikan angket kepada setiap peserta.

b. Evaluasi proses bertujuan untuk mengetahui reaksi dan kemampuan peserta dalam mengikuti pelatihan. Penilaian ini dilakukan dengan cara mengamati siswa secara individu ketika merespon materi pelatihan praktik.

c. Evaluasi akhir dilakukan dengan tujuan untuk mengetahui pemahaman, kemampuan peserta ketika mempraktikkan alat musik tradisional Lampung (Gamolan). Evaluasi selain dengan angket peserta juga mempraktikkan memainkan alat musik Gamolan, 
Rebana.

\section{Pelaksanaan dan Jadwal Kegiatan}

Tabel 3. MATERI dan JADWAL PELATIHAN SENI MUSIK TANGGAL 07 Agustus 2020

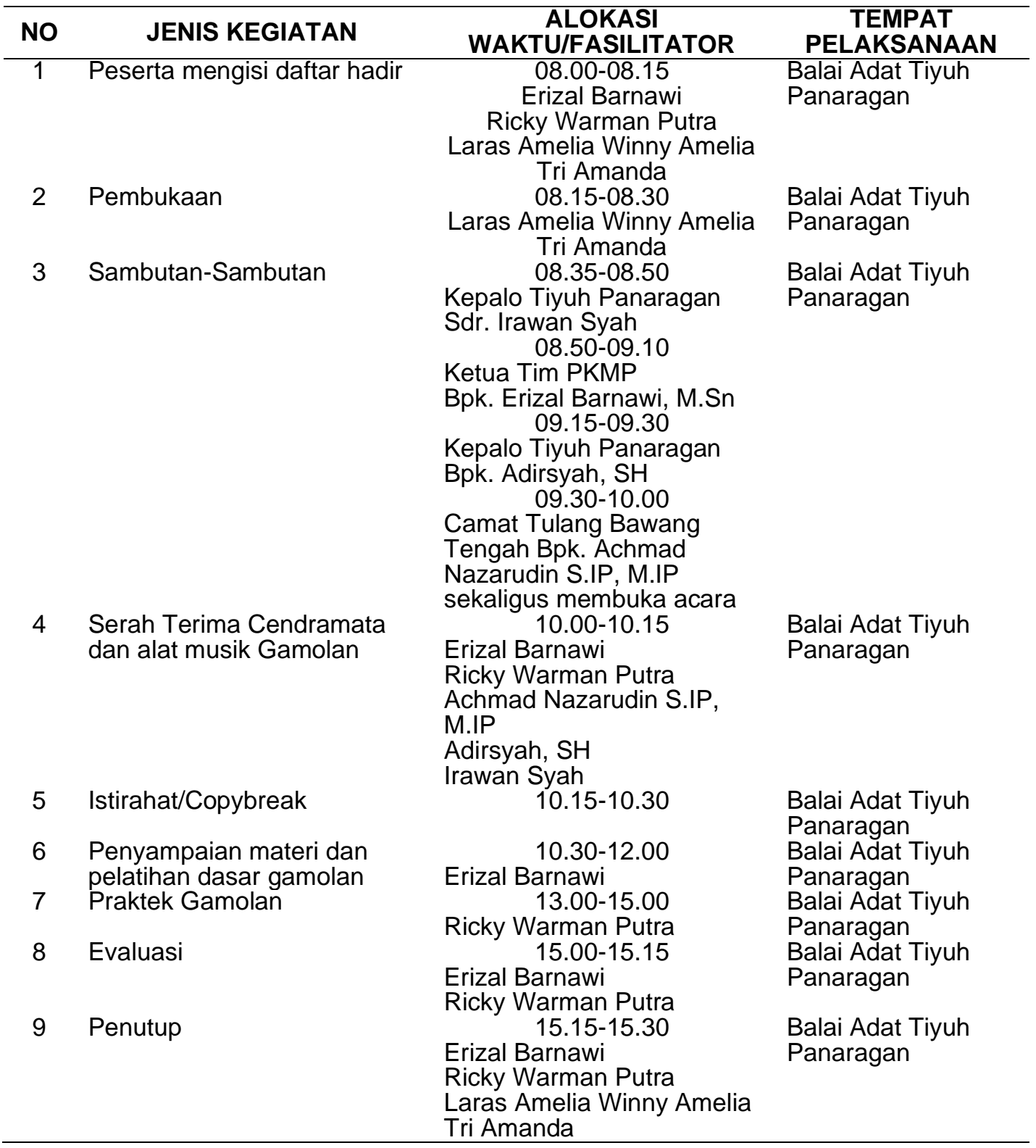

Tabel 4. MATERI dan JADWAL PELATIHAN SENI MUSIK TANGGAL 08 Agustus 2020

\begin{tabular}{|c|c|c|c|}
\hline NO & JENIS KEGIATAN & $\begin{array}{c}\text { ALOKASI } \\
\text { WAKTU/FASILITATOR }\end{array}$ & $\begin{array}{c}\text { TEMPAT } \\
\text { PELAKSANAAN }\end{array}$ \\
\hline 1 & Peserta mengisi daftar hadir & \begin{tabular}{l}
\multicolumn{2}{c}{$08.00-08.15$} \\
Erizal Barnawi \\
Ricky Warman Putra \\
Laras Amelia Winny Amelia \\
Tri Amanda
\end{tabular} & $\begin{array}{l}\text { Balai Adat Tiyuh } \\
\text { Panaragan }\end{array}$ \\
\hline 2 & Pembukaan & $\begin{array}{l}\quad 08.15-08.30 \\
\text { Laras Amelia Winny Amelia } \\
\text { Tri Amanda }\end{array}$ & $\begin{array}{l}\text { Balai Adat Tiyuh } \\
\text { Panaragan }\end{array}$ \\
\hline 3 & Evaluasi awal & $\begin{array}{l}\text { 08.30-09.00 } \\
\text { Erizal Barnawi } \\
\text { Ricky Warman Putra }\end{array}$ & $\begin{array}{l}\text { Balai Adat Tiyuh } \\
\text { Panaragan }\end{array}$ \\
\hline 4 & $\begin{array}{l}\text { Penyampaian materi dan } \\
\text { pelatihan dasar gamolan }\end{array}$ & $\begin{array}{c}09.00-10.30 \\
\text { Erizal Barnawi }\end{array}$ & $\begin{array}{l}\text { Balai Adat Tiyuh } \\
\text { Panaragan }\end{array}$ \\
\hline
\end{tabular}




\begin{tabular}{|c|c|c|c|}
\hline 5 & Istirahat & $10.30-10.45$ & \multirow{4}{*}{$\begin{array}{l}\text { Balai Adat Tiyuh } \\
\text { Panaragan } \\
\text { Balai Adat Tiyuh } \\
\text { Panaragan } \\
\text { Balai Adat Tiyuh } \\
\text { Panaragan } \\
\text { Balai Adat Tiyuh } \\
\text { Panaragan }\end{array}$} \\
\hline 6 & Praktek Gamolan & $10.45-12.00$ & \\
\hline 7 & Praktek Gamolan & $13.00-14.00$ & \\
\hline 8 & Evaluasi & $\begin{array}{c}14.00-14.15 \\
\text { Erizal Barnawi }\end{array}$ & \\
\hline 9 & Penutup & $\begin{array}{l}\text { Ricky Warman Putra } \\
\quad 14.15-14.30 \\
\text { Erizal Barnawi } \\
\text { Ricky Warman Putra } \\
\text { Laras Amelia Winny Amelia } \\
\text { Tri Amanda }\end{array}$ & $\begin{array}{l}\text { Balai Adat Tiyuh } \\
\text { Panaragan }\end{array}$ \\
\hline \multicolumn{4}{|c|}{ Tabel 5. MATERI dan JADWAL PELATIHAN SENI MUSIK TANGGAL 09 Agutsus 2020} \\
\hline NO & JENIS KEGIATAN & $\begin{array}{c}\text { ALOKASI } \\
\text { WAKTU/FASILITATOR }\end{array}$ & $\begin{array}{c}\text { TEMPAT } \\
\text { PELAKSANAAN }\end{array}$ \\
\hline 1 & Peserta mengisi daftar hadir & $\begin{array}{l}\quad 08.00-08.15 \\
\text { Erizal Barnawi } \\
\text { Ricky Warman Putra } \\
\text { Laras Amelia Winny Amelia } \\
\text { Tri Amanda }\end{array}$ & $\begin{array}{l}\text { Balai Adat Tiyuh } \\
\text { Panaragan }\end{array}$ \\
\hline 2 & Pembukaan & $\begin{array}{l}\quad 08.15-08.30 \\
\text { Laras Amelia Winny Amelia } \\
\text { Tri Amanda }\end{array}$ & $\begin{array}{l}\text { Balai Adat Tiyuh } \\
\text { Panaragan }\end{array}$ \\
\hline 3 & Evaluasi awal & $\begin{array}{l}\text { 08.30-09.00 } \\
\text { Erizal Barnawi } \\
\text { Ricky Warman Putra }\end{array}$ & $\begin{array}{l}\text { Balai Adat Tiyuh } \\
\text { Panaragan }\end{array}$ \\
\hline 4 & $\begin{array}{l}\text { Penyampaian materi dan } \\
\text { pelatihan dasar gamolan }\end{array}$ & $\begin{array}{c}09.00-10.30 \\
\text { Erizal Barnawi }\end{array}$ & \multirow{5}{*}{$\begin{array}{l}\text { Balai Adat Tiyuh } \\
\text { Panaragan } \\
\text { Balai Adat Tiyuh } \\
\text { Panaragan } \\
\text { Balai Adat Tiyuh } \\
\text { Panaragan } \\
\text { Balai Adat Tiyuh } \\
\text { Panaragan } \\
\text { Balai Adat Tiyuh } \\
\text { Panaragan }\end{array}$} \\
\hline 5 & Istirahat & $10.30-10.45$ & \\
\hline 6 & Praktek Gamolan & $\begin{array}{c}10.45-12.00 \\
\text { Erizal Barnawi }\end{array}$ & \\
\hline 7 & Praktek Gamolan & $\begin{array}{r}13.00-14.00 \\
\text { Ricky Warman Putra }\end{array}$ & \\
\hline 8 & Evaluasi & $\begin{array}{l}14.00-14.15 \\
\text { Erizal Barnawi } \\
\text { Ricky Warman Putra }\end{array}$ & \\
\hline 9 & Penutup & $\begin{array}{l}\quad 14.15-14.30 \\
\text { Erizal Barnawi } \\
\text { Ricky Warman Putra } \\
\text { Laras Amelia Winny Amelia } \\
\text { Tri Amanda }\end{array}$ & $\begin{array}{l}\text { Balai Adat Tiyuh } \\
\text { Panaragan }\end{array}$ \\
\hline
\end{tabular}

\section{HASIL DAN PEMBAHASAN}

\section{Hasil}

Jumlah peserta pelatihan dari awal hingga berakhirnya pelatihan ini 30 orang, dari 30 orang tersebut setelah penyebaran angket hanya $50 \%$ yang mengetahui salah satu musik tradisional Lampung, muda-mudi yang mengetahui tersebut belum pernah mempelajari musik tradisional Lampung, jadi bisa dikatakan hampir seluruh peserta belum memiliki pengalaman dalam belajar alat musik tradisional Lampung terkhusus Gamolan. Adapun ketertarikan seluruh peserta tentang musik tradisional Lampung sangat baik. 
Tabel 6. Perbedaan Skor Tes Awan dan Akhir

\begin{tabular}{cccc}
\hline Subjek & $\mathbf{X} \mathbf{1}$ & $\mathbf{X 2}$ & $\mathbf{D}$ \\
\hline 1 & 10 & 20 & -10 \\
2 & 10 & 20 & -10 \\
3 & 11 & 20 & -9 \\
4 & 11 & 20 & -10 \\
5 & 10 & 20 & -9 \\
6 & 11 & 20 & -9 \\
7 & 11 & 20 & -9 \\
8 & 11 & 20 & -9 \\
9 & 11 & 15 & -5 \\
10 & 10 & 15 & -5 \\
11 & 10 & 20 & -9 \\
12 & 11 & 20 & -9 \\
13 & 11 & 20 & -9 \\
14 & 11 & 15 & -5 \\
15 & 10 & 15 & -5 \\
16 & 10 & 15 & -5 \\
17 & 10 & 15 & -5 \\
18 & 10 & 20 & -9 \\
19 & 11 & 20 & -10 \\
20 & 11 & 20 & -9 \\
21 & 11 & 20 & -9 \\
22 & 11 & 20 & -9 \\
23 & 11 & 20 & -9 \\
24 & 11 & 20 & -8 \\
25 & 12 & 20 & -8 \\
26 & 12 & 20 & -8 \\
27 & 10 & 20 & -10 \\
28 & 10 & 20 & -10 \\
29 & 11 & 20 & -9 \\
30 & 11 & 20 & -10 \\
$\mathrm{n}=30$ & 339 & 480 & -161 \\
\hline & & & \\
& & &
\end{tabular}

Ket:Subjek : Peserta Pelatihan

$\mathrm{n} \quad$ : jumlah peserta pelatihan

X1 : skor tes awal

X2 : skor tes akhir

D : perbedaan skor tes awal dan akhir

\section{Evaluasi Akhir}

Evaluasi Gamolan musik tradisional Lampung dengan tabuhan sangat meningkat. Hampir seluruh peserta mampu memainkan Gamolan alat musik tradisional Lampung sesuai dengan yang diharapkan nara sumber.

\section{KESIMPULAN DAN SARAN}

\section{Kesimpulan}

Pelaksanaan kegiatan pengabdian kepada masyarakat ini merupakan kegiatan yang berhubungan erat dengan proses belajar mengajar di sekolah khususnya pada mata pelajaran seni musik. Pelatihan ini bertujuan untuk meningkatkan kemampuan dan kepekaan artistik seorang muda-mudi,sehingga bisa menjadi pengajar yang professional terutama terhadap pelajaran seni musik tradisional Lampung yaitu gamolan.

Pelatihan yang dilaksanakan ini telah mencapai sasaran. Tujuan pelatihan yang dipaparkan pada pendahuluan telah tercapai yaitu memberi pemahaman, keterampilan 
kepada Forum Mulei Menganai Panaragan Tiyuh Panaragan Kecamatan Tulang Bawang Tengah, Kabupaten Tulang Bawang Barat terhadap materi Gamolan alat musik tradisional Lampung.

\section{Saran}

Hasil dari pelatihan yang menunjukan peningkatan ini hendaknya ditindak lanjuti dengan menitikberatkan pada kondisi yaitu masih sedikitnya sekolah-sekolah yang mempunyai alat musik Gamolan. Sehingga Muda-mudi belum bisa menyalurkan apa yang di dapat dari pelatihan ini. Kegiatan ini diharapkan tidak hanya berhenti sampai disini namun ada tindak lanjut dari kedua belah pihak baik komunitas maupun perguruan tinggi Universitas Lampung. pembinaan-pembinaan lebih lanjut guna mewadahi muda-mudi yang memiliki minat terhadap seni musik. Muda-mudi yang memiliki kemampuan lebih dalam bidang seni hendaknya terus dibina guna mempersiapkan sumber daya manusia yang mampu bersaing agar kesenian lokal atau daerah tetap bisa dipertahankan.

\section{DAFTAR PUSTAKA}

[1] Hamalik, O. (2012). Kurikulum dan Pembelajaran. Jakarta: PT. Bumi Aksara.

[2] Gilakjani, A. P. (2012). Visual, auditory, kinaesthetic learning styles and their impacts on English language teaching. Journal of studies in education, 2(1), 104-113.

[3] Joyce, B., and Marsha, W. (1980). Models of Teaching (Second Edition). Englewood Cliffs, New Jersey: Prentice-Hall, Inc. 